\section{Short-circuiting DCs in atherosclerosis}

\section{By Tim Fulmer, Senior Writer}

A team of European researchers has identified a way to target proinflammatory dendritic cells that contribute to atherosclerotic plaques in mice. ${ }^{1}$ Carolus Therapeutics Inc. has a nonexclusive option to license the findings and believes the data may point to a new strategy for treating inflammation associated with cardiovascular and pulmonary disorders.

Multiple types of immune cells contribute to the proinflammatory pathology of atherosclerosis. Although macrophages are probably the best known cell type, other contributors include $\mathrm{T}$ cells and dendritic cells (DCs). ${ }^{2}$

Increased accumulation of DCs had been seen in the vessel walls of atherosclerotic mice ${ }^{3}$ and in advanced plaques from patients. ${ }^{4}$ An open question was which chemokines or cytokines are responsible for recruiting and activating those DCs.

Thus, a team led by Christian Weber, director of the Institute for Cardiovascular Prevention at Aachen University and cofounder of Carolus, set out to identify the signaling molecules responsible for DC recruitment.

The group focused on chemokine CC motif ligand 17 (CCL17), which other researchers previously identified in human atherosclerotic plaques. ${ }^{5}$ CCL17 also caught the eye of Weber and colleagues because it is expressed almost exclusively on $\mathrm{DCs}^{6}$ and therefore could play a key role in recruiting those cells to atherosclerotic plaques.

In apolipoprotein $E(A \mathrm{Aoe})^{-/-}$mice fed a high-fat diet-the standard rodent model of atherosclerosis-Weber's group found that DCs expressing $\mathrm{Ccl17}$ accumulated in atherosclerotic lesions and that knockout of Ccl17 decreased lesion formation compared with that in control mice expressing Ccl17.

Those findings suggested CCL17 was at least partly responsible for recruiting DCs to atherosclerotic lesions and that blocking CCL17 could reduce lesion size and help treat disease.

Indeed, in the same atherosclerotic mice, an anti-CCL17 antibody decreased lesion formation in the aorta compared with a control antibody.

In conclusion, the authors wrote, "DC-derived CCL17 may represent an attractive molecular target that can be translated into new therapeutics for preventing atheroprogression and treating advanced atherosclerosis."

\section{Going pulmonary}

"Targeting CCL17 may turn out to be a general anti-inflammatory strategy for blocking the effects of dendritic cells not only in atherosclerosis but also in other vascular and pulmonary diseases," said Court Turner, president, CEO and director of Carolus. Turner also is a partner at Avalon Ventures.

Turner said the new data "are very strong and a good fit with the focus of our pipeline on cytokine-targeting therapies. At this time, however, we haven't the bandwidth to start a CCL17 program."

In addition to the nonexclusive option to the CCL17 findings, the biotech has previously licensed two programs from Weber's lab. One is the company's lead compound, CT-2009, a peptide antagonist of chemokine CC motif ligand 5 (RANTES; CCL5) and platelet factor 4 (PF4; CXCL4).

In 2009, Weber and colleagues published in Nature Medicine that the peptide decreased atherosclerotic lesions in mice. ${ }^{7}$ Carolus plans to submit an IND for CT-2009 early next year and expects to test the compound in severe asthma and pulmonary arterial hypertension (PAH).

The second licensed program, also in preclinical development, targets macrophage migration inhibitory factor (MIF). That target is upregulated in autoimmune and inflammatory diseases, including rheumatoid arthritis (RA), multiple sclerosis (MS) and asthma.

Turner said designing and running atherosclerosis trials will be difficult without a partner, and therefore the biotech initially has focused on smaller indications. "As we consider eventually licensing the CCL17 antibody, we would like to see data in animal models of pulmonary and respiratory indications. In particular, acute respiratory illness might be worth looking at, given the known association of dendritic cells with that condition," he said.

Corresponding author Weber told SciBX he wants to get a better handle on the mechanism of CCL17 signaling in inflammatory diseases, and in particular he wants to identify the receptor of CCL17 that is responsible for the effects seen in the atherosclerotic mice.

According to Weber, the findings in the paper are covered by patents and are available for licensing from Aachen University.

Fulmer, T. SciBX 4(23); doi:10.1038/scibx.2011.648

Published online June 9, 2011

REFERENCES

1. Weber, C. et al. J. Clin. Invest.; published online June 1, 2011; doi: $10.1172 / \mathrm{JCl} 44925$

Contact: Alma Zernecke, University of Wuerzburg,

Wuerzburg, Germany

e-mail: alma.zernecke@virchow.uni-wuerzburg.de

Contact: Christian Weber, Aachen University, Aachen, Germany e-mail: christian.weber@med.uni-muenchen.de

2. Weber, C. et al. Nat. Rev. Immunol. 8, 802-815 (2008)

3. Liu, P. et al. Arterioscler. Thromb. Vasc. Biol. 28, 243-250 (2008) 


\section{ANALYSIS}

4. Bobryshev, Y.V. et al. Eur. Heart J. 26, 1700-1704 (2005)

5. Greaves, D.R. et al. Arterioscler. Thromb. Vasc. Biol. 21, 923-929 (2004)

6. Alferink, J. et al. J. Exp. Med. 197, 585-599 (2003)

7. Koenen, R.R. et al. Nat. Med. 15, 97-103 (2009)

\section{TARGETS \& MECHANISMS}

COMPANIES AND INSTITUTIONS MENTIONED

Aachen University, Aachen, Germany

Avalon Ventures, La Jolla, Calif.

Carolus Therapeutics Inc., San Diego, Calif. 